Brit. J. prev. soc. Med. (1976), 30, 180-186

\title{
A study of the validity of the Hospital Activity Analysis information
}

\author{
C. J. M. MARTINI, A. O. HUGHES, AND V. A. PATTON \\ Department of Community Health, Medical School, Nottingham University
}

\begin{abstract}
Martini, C. J. M., Hughes, A. O., and Patton, V. A. (1976). British Journal of Preventive and Social Medicine, 30, 180-186. A study of the validity of the Hospital Activity Analysis information. For a number of years the medical profession and its administrators have been using statistical tabulations from the Hospital Activity Analysis returns. The quality of this information has often been criticized and no attempt has been made to quantify the levels of 'errors' in England and Wales. This paper reports the findings of such a study in Nottingham, and concludes that the Hospital Activity Analysis system in that area is almost as good as the clinical notes from which it is derived.
\end{abstract}

The creation of a uniform reporting system for hospital data has been an objective of the health service from the very beginning. As early as 1859 Florence Nightingale proposed that all London hospitals should use a uniform system (Nightingale, 1859), but the great burst of activity in hospital data systems has occurred only in the last 15 years.

Hospital discharges provide the 'hardest' data prepared on a continuous basis for analysing morbidity. Hospitalization is a distinct and easily quantifiable concept; other relevant features of the patient-such as diagnosis, age, sex, and residencecan be routinely collected and form an increasingly important part of hospital information systems. These data often contain enough information to permit the development of indicators of both the social and the functional status of patients. Furthermore, although some conceptual and technical problems in data linkage remain, it is now feasible to relate successive health events in one individual.

The potential usefulness of hospital information systems in the study of certain aspects of medical care has prompted this project. Although the results from the specific area which we have studied (two-thirds of Nottinghamshire) would not necessarily apply in other areas of the country, they should provide an estimate of the general quality of the hospital information available and the possible areas of concern.
In 1969 the Hospital Activity Analysis (HAA) introduced on a national scale in England Wales (Rowe and Brewer, 1972) with the follow objective:

to provide for doctors and administrators both at hospital level and in the Boards, ap information system in which details relating to individual patients are brought togethero for analysis; these include clinical data relating to diagnosis and operations, and patiene characteristics such as sex, age, marital status, and area of residence, as well as administrative information about admission, length of stay: and discharge. As far as records are concerned this need not involve doctors in anything more than the supervision of the entry of clinical information in the summary form. (Department of Health and Social Security: 1969).

The HAA system uses the patient's medicaf file as the source of data. Different items of information-such as residence, age, diagnoses, operations, disposal, etc--about each hospitah inpatient discharged are extracted from the file and recorded on a special form, which is basically an identification sheet showing the patient's $N$ personal particulars in a standard order. The form then serves as a source document for computero processing. Reports about all discharges from hospitals in England and Wales will be published? 
periodically, based on these data, and returns are already available for many hospitals.

Until now, very little has been known about the quality and completeness of HAA data. The accuracy of the data from the Scottish Hospital In-Patient Statistics has been examined (Lockwood, 1971a). Many errors were reported in recording the patient's area of residence and fewer errors in other items, such as operation, subsidiary diagnosis, and patient's occupation. In addition, some items in HAA for South Wales have recently been studied in connexion with the efficient use of blood (McNeilly and Moore, 1975). No other work has been published on the accuracy of the information recorded for the HAA for England and Wales.

\section{Objective AND Methods}

With the objective of checking the accuracy of HAA data in the area around Nottingham, the authors made an analysis of a random sample of all 1972 HAA records for three Hospital Management Committees (HMCs) in Nottinghamshire and this paper presents the first results of the study.

A systematic sample of one in 100 hospital discharges was taken and data abstracted from these clinical notes were compared with the HAA tape produced by the Regional Health Authorities. The study involved 29 hospitals serving a population of just under one million. Of these, 16 were classed as short stay and 13 as long stay hospitals. There were 73940 HAA records relating to these hospitals for 1972. The bulk of the field work was undertaken from December 1973 to April 1974, but further validity checks extended this period until the end of 1974.

Nine medical students in their fourth year and two in their second year were responsible for abstracting the preliminary data on to specially prepared forms which duplicated most of the items on the form HMR1 used by the hospitals to record particulars for HAA. The students were given preliminary training and issued with a manual of procedures containing the exact definitions set out by the Regional Health Authorities for use in all hospitals. Students were instructed to extract all information from the clinical notes, ignoring the filed copy of the HMR1 form. Reference to this form by the abstracting student was expressly forbidden. However, it is not possible to check whether reference to the form was ever made and this is thus a possible source of error in the method; such improper checking would tend to increase concordance. Within each HMC one of the students acted as a supervisor for the others and recording was also monitored continually by the authors. No attempt was made to evaluate, in medical terms, the accuracy of diagnoses or operations in the clinical notes.

The review of the medical records was done in a series of steps. In the first instance, the students were asked to complete a form for each record included in the sample and were given only the hospital number, unit number, and date of admission (this last item to be used if the patient had been admitted more than once in any particular year). To avoid possible bias, no other details from the HAA computer tape were released to the students. Successive attempts were made to complete the review of all records included in the sample. However, a proportion of them $(5.5 \%)$ had still not been traced 12 months later, in spite of all efforts of the research team and hospital authorities. The forms completed by the students were then coded by the research team and compared with the data available about the same patients on the HAA tape.

When a difference in any item was found, and inconsistencies in the information could not be satisfactorily resolved, further clarification was sought in a second review of the medical notes. In these cases, a second abstract of the items in question was taken from the notes by a member of the research team who had not been involved in the previous stage. No information previously extracted was given to these workers. These items were then re-checked against the tape and the previous form and a final decision made. If doubt still existed on the correct interpretation of the case notes, the benefit was given to the HAA tape. This would of course, tend to increase concordance, but in only a very small number of records (less than $1 \%$ ) was this criterion used.

\section{RESULTS}

It was considered unnecessary, in view of the purpose of this study to name the particular HMCs involved. In this paper they are therefore identified only by letters in the text and in the subsequent tables. As we have already mentioned, it was not possible to trace from the information given (hospital number and date of admission) all the medical records in the $1 \%$ sample. The number of records reviewed, together with all the other basic data, are presented in Table I. The proportion of missing records was significantly lower in HMC 'B' $(P<0 \cdot 01)$. 
TABLE I

NUMBER OF RECORDS AND ITEMS REVIEWED AND THEIR CONSISTENCY WITH HAA INFORMATION CLASSIFIEI BY THREE HMCs

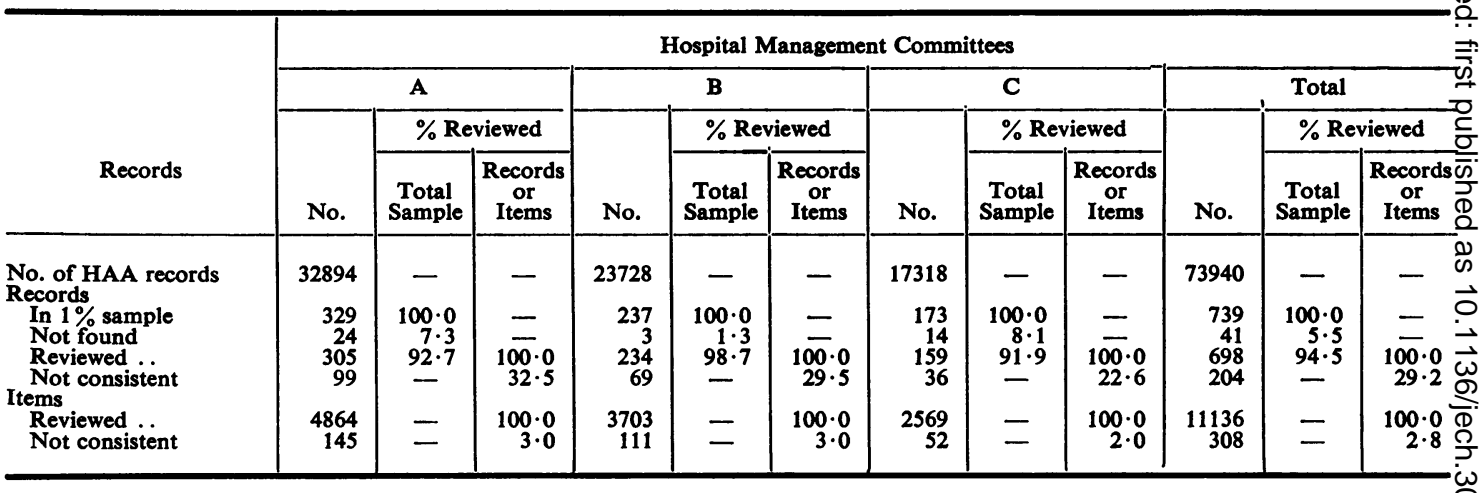

The results show that in approximately $30 \%$ of the sample of records examined there was lack of complete agreement between the HAA tape and the validated contents of the hospital notes. The differences between the HMCs were small and not statistically significant. However, when lack of concordance is viewed in terms of differences in individual items entered on the HAA form, the overall 'error' rate (or lack of concordance) falls to just under $3 \%$, with HMC ' $\mathrm{C}$ ' performing significantly better than the two other committees $(\mathrm{P}<0.05) .70 \%$ of records in 'error' had only one item incorrect, while less than $3 \%$ of records in 'error' had four or more incorrect items.

For the purpose of this presentation, the HAA return has been considered to contain two types of information; demographic features and medicoadministrative data. The results indicate (Tables II and III) that differences exist in both types of data, with two HMCs showing significantly loweroo levels of overall demographic error than the third $(\mathrm{P}<0.05)$. There is a larger variation in the "error's values for medico-administrative data, HMC having only half the total error of HMC 'B'. $\$$ ' all the individual items reviewed the only signif cant differences in statistical terms $(P<0 \cdot Q 5)$ occur between HMCs in the cases of maritap status, transfers, and date placed on waiting list.

In order to give weighting to the types of differences found, it was decided to produceōa. 'refined' or 'important' error rate for each HME. This refinement consisted of accepting as permissible, errors of the following types:

1. Differences of less than $\mathbf{3 0}$ days in the date of birth or date of being placed on waiting list

2. Differences of area of residence coding if the quoted local authority was contiguous to the

TABLE II

INCONSISTENCIES IN DEMOGRAPHIC DATA BETWEEN THE CLINICAL NOTES AND HAA INFORMATION CLASSIFIED BY THREE HMCS

\begin{tabular}{|c|c|c|c|c|c|c|c|c|c|c|c|c|}
\hline & \multicolumn{2}{|c|}{ No. of Items } & \multirow{2}{*}{$\begin{array}{c}\begin{array}{c}\% \text { of } \\
\text { Items }\end{array} \\
\begin{array}{c}\text { Not } \\
\text { con- } \\
\text { sistent }\end{array} \\
\end{array}$} & \multicolumn{2}{|c|}{ No. of Items } & \multirow{2}{*}{ 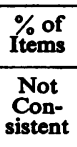 } & \multicolumn{2}{|c|}{ No. of Items } & \multirow{2}{*}{ 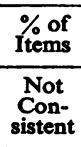 } & \multicolumn{2}{|c|}{ No. of Items } & \multirow{2}{*}{\begin{tabular}{|c|}
$\begin{array}{c}\% \text { of } \\
\text { Items }\end{array}$ \\
$\begin{array}{c}\text { Not } \\
\text { Con- } \\
\text { sistent }\end{array}$ \\
\end{tabular}} \\
\hline Data & $\begin{array}{c}\text { Re- } \\
\text { viewed }\end{array}$ & $\underset{\begin{array}{c}\text { Not } \\
\text { sistent }\end{array}}{\text { Con- }}$ & & $\begin{array}{c}\mathrm{Re}- \\
\text { viewed }\end{array}$ & $\underset{\begin{array}{c}\text { Con- } \\
\text { sistent }\end{array}}{\text { Non }}$ & & $\begin{array}{c}\text { Re- } \\
\text { viewed }\end{array}$ & $\begin{array}{c}\text { Not } \\
\text { Con- } \\
\text { sistent }\end{array}$ & & $\begin{array}{c}\mathrm{Re}- \\
\text { viewed }\end{array}$ & $\begin{array}{c}\text { Not } \\
\text { Con- } \\
\text { sistent }\end{array}$ & \\
\hline Total & 1525 & 58 & $3 \cdot 8$ & 1170 & 29 & $2 \cdot 5$ & 795 & 23 & $2 \cdot 9$ & 3490 & 110 & $3 \cdot 2$ \\
\hline
\end{tabular}


TABLE III

INCONSISTENCIES IN MEDICO-ADMINISTRATIVE DATA BETWEEN CLINICAL NOTES AND HAA INFORMATION CLASSIFIED BY THREE HMCS

\begin{tabular}{|c|c|c|c|c|c|c|c|c|c|c|c|c|}
\hline \multirow[b]{4}{*}{ Clinical Data } & \multicolumn{12}{|c|}{ Hospital Management Committees } \\
\hline & \multicolumn{3}{|c|}{$\mathbf{A}$} & \multicolumn{3}{|c|}{ B } & \multicolumn{3}{|c|}{$\mathbf{C}$} & \multicolumn{3}{|c|}{ Total } \\
\hline & \multicolumn{2}{|c|}{ No. of Items } & \multirow{2}{*}{$\begin{array}{c}\begin{array}{c}\% \text { of } \\
\text { Items }\end{array} \\
\begin{array}{c}\text { Not } \\
\text { Con- } \\
\text { sistent }\end{array}\end{array}$} & \multicolumn{2}{|c|}{ No. of Items } & \multirow{2}{*}{$\begin{array}{c}\begin{array}{c}\% \text { of } \\
\text { Items }\end{array} \\
\begin{array}{c}\text { Not } \\
\text { Con- } \\
\text { sistent }\end{array}\end{array}$} & \multicolumn{2}{|c|}{ No. of Items } & \multirow{2}{*}{$\begin{array}{c}\begin{array}{c}\% \text { of } \\
\text { Items }\end{array} \\
\begin{array}{c}\text { Not } \\
\text { Con- } \\
\text { sistent }\end{array}\end{array}$} & \multicolumn{2}{|c|}{ No. of Items } & \multirow{2}{*}{$\begin{array}{c}\begin{array}{r}\% \text { of } \\
\text { Items }\end{array} \\
\begin{array}{c}\text { Not } \\
\text { Con- } \\
\text { sistent }\end{array}\end{array}$} \\
\hline & $\begin{array}{c}\text { Re- } \\
\text { viewed }\end{array}$ & $\begin{array}{l}\text { Not } \\
\text { Con- } \\
\text { sistent }\end{array}$ & & $\begin{array}{c}\text { Re- } \\
\text { viewed }\end{array}$ & $\begin{array}{l}\text { Not } \\
\text { Con- } \\
\text { sistent }\end{array}$ & & $\underset{\text { viewed }}{\text { Re- }}$ & $\begin{array}{c}\text { Not } \\
\text { Con- } \\
\text { sistent }\end{array}$ & & $\underset{\text { viewed }}{\text { Re- }}$ & $\begin{array}{l}\text { Not } \\
\text { Con- } \\
\text { sistent }\end{array}$ & \\
\hline $\begin{array}{l}\text { Source of admission } \\
\text { Date on waiting list* } \\
\text { Date of admission } \\
\text { Specialty } \\
\text { Ward } \\
\text { Transfers } \\
\text { Date of discharge } \\
\text { Disposal } \\
\text { Diagnosis* } \\
\text { No. of theatre visits } \\
\text { Date of first operation* } \\
\text { Operations* }\end{array}$ & $\begin{array}{l}305 \\
109 \\
305 \\
305 \\
305 \\
305 \\
305 \\
305 \\
429 \\
305 \\
161 \\
200\end{array}$ & $\begin{array}{r}8 \\
3 \\
1 \\
1 \\
10 \\
14 \\
2 \\
4 \\
28 \\
2 \\
10 \\
4\end{array}$ & $\begin{array}{l}2 \cdot 6 \\
2 \cdot 8 \\
0 \cdot 3 \\
0 \cdot 3 \\
3 \cdot 3 \\
4 \cdot 6 \\
0 \cdot 7 \\
1 \cdot 3 \\
6 \cdot 5 \\
0 \cdot 7 \\
6 \cdot 2 \\
2 \cdot 0\end{array}$ & $\begin{array}{r}234 \\
71 \\
234 \\
234 \\
234 \\
234 \\
234 \\
234 \\
349 \\
234 \\
114 \\
127\end{array}$ & $\begin{array}{r}10 \\
12 \\
3 \\
2 \\
5 \\
6 \\
7 \\
2 \\
18 \\
4 \\
6 \\
7\end{array}$ & $\begin{array}{r}4 \cdot 3 \\
16 \cdot 9 \\
1 \cdot 3 \\
0 \cdot 9 \\
2 \cdot 1 \\
2 \cdot 6 \\
3 \cdot 0 \\
0 \cdot 9 \\
5 \cdot 2 \\
1 \cdot 7 \\
5 \cdot 3 \\
5 \cdot 5\end{array}$ & $\begin{array}{r}159 \\
63 \\
159 \\
159 \\
159 \\
159 \\
159 \\
159 \\
228 \\
159 \\
95 \\
116\end{array}$ & $\begin{array}{c}4 \\
5 \\
\\
\\
1 \\
15 \\
1 \\
1 \\
1 \\
1 \\
1\end{array}$ & $\begin{array}{l}2.5 \\
7.9 \\
0.6 \\
0.6 \\
0.6 \\
0.6 \\
1.1 \\
0.9\end{array}$ & $\begin{array}{r}698 \\
243 \\
698 \\
698 \\
698 \\
698 \\
698 \\
698 \\
1005 \\
698 \\
370 \\
443\end{array}$ & $\begin{array}{r}22 \\
20 \\
4 \\
3 \\
16 \\
20 \\
10 \\
6 \\
61 \\
7 \\
17 \\
12\end{array}$ & $\begin{array}{l}3 \cdot 2 \\
8 \cdot 2 \\
0 \cdot 6 \\
0 \cdot 4 \\
2 \cdot 3 \\
2 \cdot 3 \\
1 \cdot 4 \\
0 \cdot 9 \\
6 \cdot 9 \\
1 \cdot 0 \\
4 \cdot 6 \\
2 \cdot 7\end{array}$ \\
\hline Total & 3339 & 87 & $2 \cdot 6$ & 2533 & 82 & $3 \cdot 2$ & 1774 & 29 & $1 \cdot 6$ & 7646 & 198 & $2 \cdot 6$ \\
\hline
\end{tabular}

* Number of items reviewed based on actual number of items recorded in the clinical notes

correct area (provided this did not take the case outside the recognized hospital catchment area).

3. Differences in marital status if 'unknown' was coded.

4. Differences in source of admission if this involved booked/planned as opposed to waiting list.

5. Differences in specialty if a sub-specialty was involved.

6. Differences in transfers where maternity wards were involved.*

All other differences were considered too important to be ignored.

The exclusion of these 'permissible' errors reduced the overall demographic 'error' rates to $1 \cdot 2 \%, 0.8 \%, 1 \cdot 8 \%$, and $1.2 \%$, the medicoadministrative 'error' rates to $2 \cdot 4 \%, 2 \cdot 4 \%, 1 \cdot 1 \%$, and $2 \cdot 1 \%$, and total 'error' rates to $2 \cdot 0 \%, 1 \cdot 9 \%$, $1.3 \%$, and $1.8 \%$ respectively in the three HMCs and in the whole area. The significant difference between demographic and medico-administrative rate is now established overall and in two of the HMCs $(P<0.01)$; demographic data seem to be more reliable than medico-administrative data.

As far as patient diagnosis and surgical operations are concerned the analysis is further complicated by the fact that several types of 'error' can occur:

-One of the hospitals within Hospital Management Committee 'B' has included maternity cases in the Hospital Activity Analysis system, using the HMR1 form to this effect. non-recording, recording in an inappropriate order, or miscoding. Tables IV and V attempt to throw light on this difficulty and present the differences found. High levels of consistency were attained by all three HMCs on the first diagnosis, while the significantly increased levels of inaccurate information for second and third diagnoses must be recognized $(P<0.001)$, especially as this does not generally involve the ordering of the information.

The use of more than one person in the checking team in this study may be criticized on the grounds of possible inconsistencies between individuals. This was examined by considering the ratio of the number of records eventually found incorrect to the number initially found incorrect by each checker. There were no significant differences between the checkers on this criterion. $\dagger$

\section{Discussion AND Conclusions}

An advantage claimed for the HAA system is that it has provided a comprehensive picture of hospital morbidity and hospital utilization. However, it has several well known drawbacks (such as being case- and not patient-orientated) and it is much in need of expansion. In the past, at least four different uses for HAA have been defined: in hospital management, in patient management, in health services planning, and last, but not least,

IIt is theoretically possible that the original HAA coding was correct and that subsequent checks were consistently incorrect. The method used reduced this source of error as much as possible, although not completely. 
TABLE IV INCONSISTENCIES IN DIAGNOSTIC DATA BETWEEN CLINICAL NOTES AND HAA INFORMATION CLASSIFIED BY $\underset{\text { THREE HMCs }}{\overrightarrow{\text { S.: }}}$

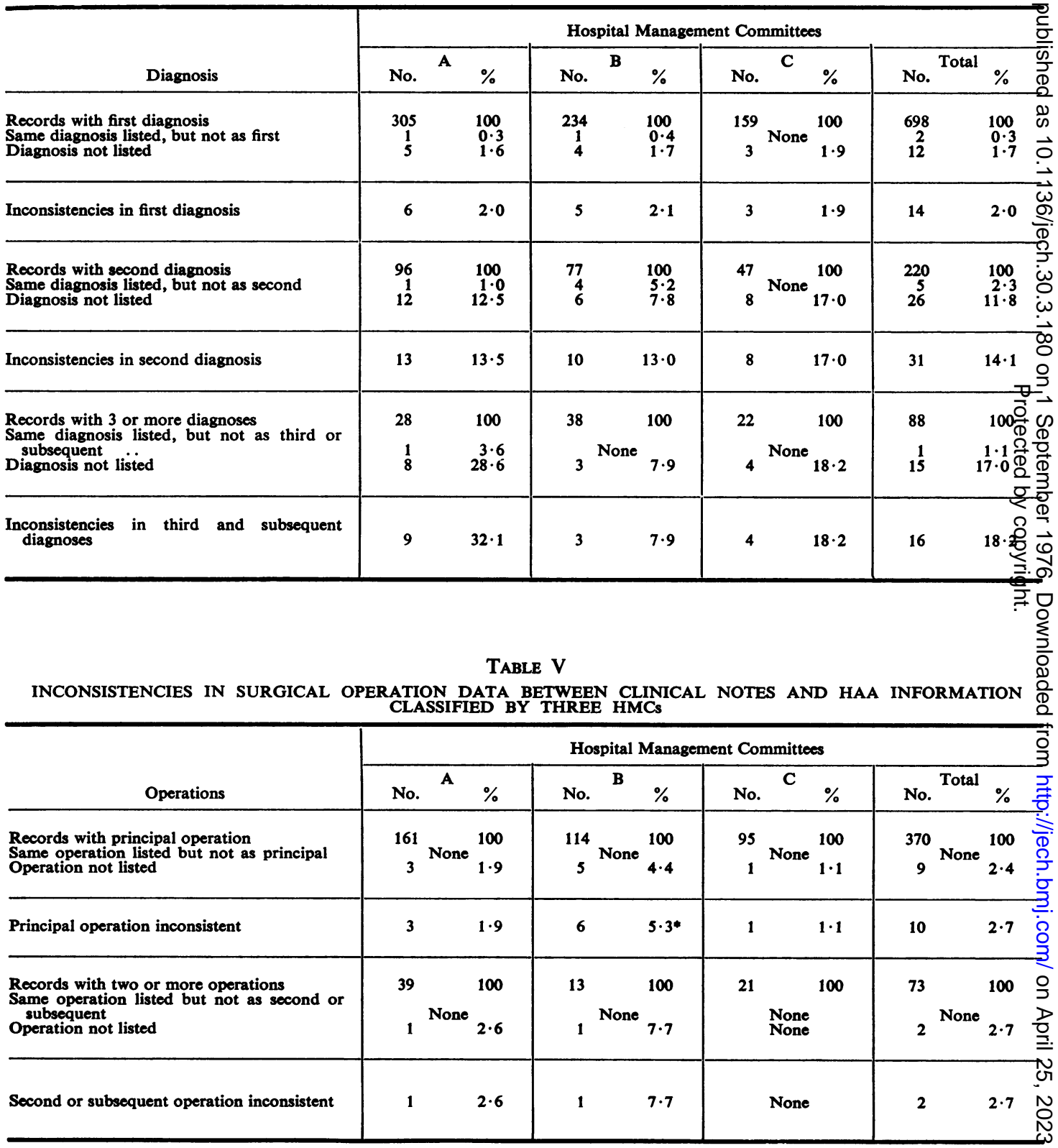

*The number of records considered inconsistent was increased by the mention of a principal operation in the $H A A$ tape, which was nof mentioned in the clinical notes as such 
in medical care and epidemiological research (US Public Health Service, 1963; White, 1967; Bonnet, 1970; Peterson, 1970; Lockwood, 1971b; Ashley, 1972). All of these, particularly the use in research, are likely to expand in scope and importance and with this expansion the validity of the data will become more critical. While it is probable that a similar pattern of inconsistencies will exist in other regions (although not necessarily with the same proportion of error, since the Trent Regional Authorities have a highly efficient data checking process in their computerized HAA system) the important errors (in the light of its main uses) are surprisingly low and this offers strong support for confidence.

Comparisons with the results of the Lockwood study in Scotland are both reassuring and encouraging. The pattern of inconsistencies is similar, although in every item the proportion of error is smaller. Continual use of the system could be expected to improve its quality.

The analysis and comparison of three different HMCs shows that in the main the differences are consistent, suggesting a systematic error perhaps in the definition of how to collect information. This may be particularly relevant to multiple diagnoses, operations, and transfers where clerical assistants need very clear guidelines and probably more training in take-off and coding procedures.

We have interpreted the relative importance of the items, and hence of any inconsistencies between the original records and the HAA data derived from them, in terms of our own interest in epidemiological applications, and our attempt to refine the amount of error was of course biased towards this use of the data. Although this was not explicitly included among the stated objectives at the time of the introduction of HAA we believe that such abstracts can offer substantial information for research, although the limitations are severe. Unless the high rates of unrecorded information about second and subsequent diagnoses and operations can be improved, cases will be seriously underestimated and incidence and prevalence rates, or diagnostic registers, will be unreliable. If the area of residence is miscoded, the calculation of rates could involve errors in both the numerators (the number of cases) and the denominators (the definition of the catchment areas).

Dangers of distortion also exist of course in using only principal diagnoses as a source of mortality or morbidity rates. There is a tendency to interpret the single diagnosis at admission in the same way as principal diagnosis on the death certificate in spite of the obvious risk that the diagnoses may be changed during the patient's stay in the hospital. It is possible that many doctors have not yet given sufficient consideration to this risk.

We feel that in terms of accuracy the HAA system is almost as good as the clinical notes from which it is derived and has many advantages of uniformity and automation that other medical information systems do not possess. Within the region from which this study was derived, even more checks have been added to the HAA processing system than when our data were collected in 1972. From our experience we would recommend that more careful training be given to the personnel involved with HAA at hospital level in order to improve the standardization of their recording. We feel that the mistrust frequently expressed by consultants in the information produced from HAA should be directed more towards the quality of the original medical notes than to the HAA system itself which, from the results of this study, seem to be quite a good reproduction of what is contained in them. Doctors are involved in the supervision of the entry of clinical information in the summary form and if the medical profession wants correct evidence from the HAA system, it must ensure that correct evidence is clearly presented to the HAA clerks.

The authors wish to express their thanks to the Trent Regional Health Authority; to the Hospital Management Committees of Nottinghamshire, in particular the Medical Records Officers, to the medical students involved in the abstracting of information from the clinical notes, and to the data processing and clerical staff of the Department of Community Health, Nottingham Medical School without whose co-operation this study would not have been possible.

Requests for reprints: C. J. M. Martini, Senior Lecturer, Department of Community Health, Medical School, Nottingham University.

\section{REFERENCES}

Ashley, J. S. A. (1972). Present state of statistics from hospital in-patient data and their uses. Brit. J. prev. soc. Med., 26, 135.

BonNeT, P. D. (1970). Data collection requirements for health services research. Medical Care, VIII, 4, Suppl., 199.

Department of Health and Social Security (1969). Hospital Activity Analysis Circular HM (69) 79. DHSS, London.

Lockwood, E. (1971a). Accuracy of Scottish hospital morbidity data. Brit. J. prev. soc. Med., 25, 76.

(1971b). Scottish hospital morbidity data, 1961-68. Scottish Home and Health Department, vol. 20. 
MCNeILly, R. H. and Moore, F. (1975). The accuracy of some Hospital Activity Analysis data. Hosp. Hlth Serv. Rev., 71, 93.

Nightingale, F. (1859). Notes on Hospitals. Parker and Sons, London.

Peterson, O. L. (1970). Information needs for regional planning. Medical Care, VIII, 4, Suppl., 187.

Rowe, R. G. and BrewER, W. (1972). Hospital Activity Analysis. Butterworths, London.
US Public Health Service (1963). Conference of Research in Hospital Use, sponsored by the American Hospital Association, and the Public Health Servico at Chicago, Ill., 22-23 January, 1963. Public Health. Publications, No. 930-E-2, Washington, DC.

WhrTe, K. L. (1967). Improved medical care statistice

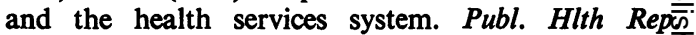
(Wash.), 82, 847. 